\title{
ChemComm
}

\section{Total synthesis of kottamide E†}

Cite this: Chem. Commun., 2013, 49, 2296

Received 19th December 2012,

Accepted 1st February 2013

DOI: $10.1039 / \mathrm{c} 3 \mathrm{cc} 39062 d$

www.rsc.org/chemcomm

The first synthesis of kottamide $E$, a marine natural product containing a 5,6-dibromoindole linked via a (Z)-enamide to an unusual 1,2-dithiolane-containing amino acid, is reported.

Kottamide E (1), isolated as a minor component from the New Zealand ascidian Pycnoclavella kottae in 2003 by Appleton and Copp, is the only natural product reported to date containing the unusual 4-amino-1,2-dithiolane-4-carboxylic acid residue. ${ }^{1}$ Related mono- and dibrominated $Z$-enamide-containing indole alkaloids, kottamides A-D, isolated from the same source, have been shown to exhibit anti-inflammatory, antitumour and antimetabolic activities. ${ }^{2}$ Given the paucity of the natural product and absence of biological data, we have investigated a total synthesis of kottamide E, which we report herein.

Retrosynthetically we envisaged that union of a protected $(Z)$-enamide 2 with an appropriate oxalic acid derivative and the amide 3 offered a viable approach to kottamide A (Scheme 1). The synthetically challenging, thermodynamically less stable $(Z)$-enamide 2 was planned to arise from reaction of a vinyl isocyanate with 2-trimethylsilylethanol, the isocyanate in turn produced from Curtius rearrangement of an acyl azide derived from $\alpha, \beta$-unsaturated ester 4 . We were particularly attracted to this general approach ${ }^{3,4}$ to stereodefined enamides given its successful utilization in complex natural product synthesis, ${ }^{5,6}$ including indolic enamides. ${ }^{7}$ The $(Z)$-double bond geometry within 4 would be set through an appropriate HornerWadsworth-Emmons reaction of 5,6-dibromoindole 5, which we have previously shown can be readily accessed in 3 steps from commercially available methyl indole-3-carboxylate via regioselective dibromination. ${ }^{8-10}$

Although the Ando-modified Horner-Wadsworth-Emmons reaction $^{11}$ of 5 proceeded with no selectivity, protection of the indole nitrogen gave rise to good to excellent levels of

School of Chemistry, University of Birmingham, Edgbaston, Birmingham, B15 2TT, UK. E-mail: r.s.grainger@bham.ac.uk; Fax: +44 (0)121 4144403;

Tel: +44 (0)121 4144465

$\dagger$ Electronic supplementary information (ESI) available: Experimental procedures and analytical data for all new compounds. See DOI: 10.1039/c3cc39062d
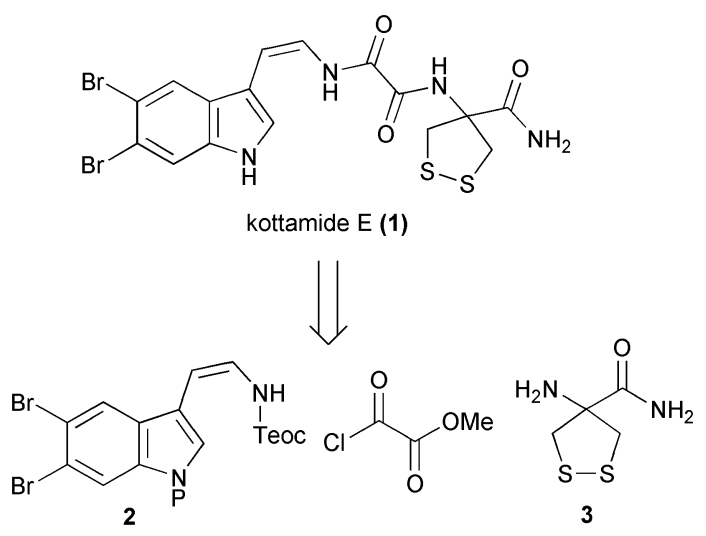

$\downarrow$<smiles>[R]OC(=O)/C=C\c1c[nH]c2cc(Br)c(Br)cc12</smiles>

4

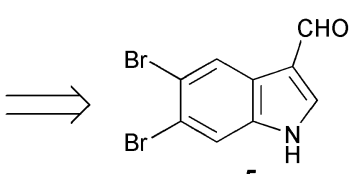

5
Scheme 1 Retrosynthetic analysis of kottamide E.

stereocontrol in favour of the expected $(Z)$-isomer 7, which could be readily separated from the corresponding $(E)$-isomer by column chromatography. Attempted ester hydrolysis of 7a-c was complicated by the faster removal of the indole protecting group and loss of integrity of the alkene double bond geometry. For example, in the case of the Boc-protected indole 7a, sodium hydroxide caused complete removal of the Boc group after 16 hours at room temperature, with no ester hydrolysis and a small amount of alkene isomerisation. Upon warming to $65{ }^{\circ} \mathrm{C}$ saponification was complete within 3 hours but the $(Z)$-alkene was completely converted to its $(E)$-isomer. Similarly the Teoc group of $\mathbf{7 b}$ and the tosyl group of $7 \mathbf{c}$ were removed within 30 and 5 minutes respectively at $0{ }^{\circ} \mathrm{C}$. However, the SEM-protected indole $\mathbf{7 d}$ could be progressed via the carboxylic acid to the acyl azide $\mathbf{8}$ with complete retention of double bond geometry.

Heating 8 in the presence of 2-(trimethylsilyl)ethanol gave the unstable Teoc-protected enecarbamate 9. This was found to 
decompose rapidly, even when stored in the freezer under an atmosphere of argon. $\mathrm{N}$-Acylation of $\mathbf{9} \mathrm{via}$ deprotonation with NaHMDS and quenching with methyl chlorooxoacetate gave methyl oxoacetate 10, which was not amenable to purification. Instead, treatment of the crude reaction mixture with TBAF afforded 11 in acceptable yield. Unfortunately the acylation step proved somewhat capricious and was not amenable to scale-up, which required recourse to multiple smaller scale reactions. The combined crude reaction mixtures were subjected to Teoc deprotection to afford 11, which is stable for several weeks at low temperature. Saponification of $\mathbf{1 1}$ gave acid $\mathbf{1 2}$ in quantitative yield.

The instability of $\mathbf{1 0}$ is consistent with the observations of Kitahara on Teoc-protected enamines appended to indoles, where $\mathrm{N}$-acylated products could not be purified until the Teoc-group had been removed. ${ }^{7}$ We observed that 10 was highly sensitive to base and that acylation was somewhat reversible: if crude $\mathbf{1 0}$ was treated with triethylamine it rapidly reverted to Teoc-protected enamide 9. It is thought that this is the reason for the modest yield of the acylation-deprotection sequence: the basic nature of TBAF can cause competitive deacylation of intermediate $\mathbf{1 0}$ to return $\mathbf{9}$.

The novel amide $\mathbf{3}$ was prepared as its hydrochloride salt in 3 steps from the known $^{12}$ protected amino acid 13 in 88\% overall yield (Scheme 2). Coupling of $\mathbf{1 3}$ with carboxylic acid 3 proceeded smoothly using HBTU in DMF at $50{ }^{\circ} \mathrm{C}$ over 3 days to afford SEM-protected kottamide E 14 in 66\% yield. Unfortunately, clean removal of the SEM group proved to be highly problematic. A wide variety of methods were tested without success. ${ }^{13}$ In each case reaction progress was followed by tlc, mass spectrometry and HPLC but we were unable to find conditions to deprotect kottamide $\mathrm{E}$ without concomitant fragmentation of the target. In most cases HPLC analysis of the reaction mixture indicated the presence of numerous by-products; mass spectrometric analysis suggested that various mono- and dibrominated fragmentation products were being formed, but sufficient material could not be isolated to confirm the identity of any such by-products. $\S$

Given the difficulties encountered in removing the SEM protecting group from 14 to unveil kottamide E, an alternative approach was devised whereby the potentially sensitive natural product would be accessed directly upon formation of the amide bond. Considering the previously observed labile nature of the tosyl protecting group in $7 \mathbf{c}$ under saponification conditions, this new approach sought to exploit the expected removal of this group alongside methyl ester hydrolysis in the penultimate step (Scheme 3).

Towards this goal, tosyl-protected indole-3-carbaldehyde 6c underwent Ando-modified Horner-Wadsworth-Emmons reaction $^{11}$ to afford (Z)-tert-butyl ester $\mathbf{1 7}$ as the major product, along with the separable (E)-isomer (Scheme 3). Hydrolysis of the ester under acidic conditions followed by reaction with DPPA gave acyl azide 18 as a 3.2 : 1 mixture of double bond isomers. Curtius rearrangement and trapping gave protected enamine 19 which was subjected to acylation and immediate deprotection to afford enamide 20. At this point the unwanted $(E)$-isomer could be removed by flash column chromatography. As expected, removal of the tosyl protecting group and concomitant
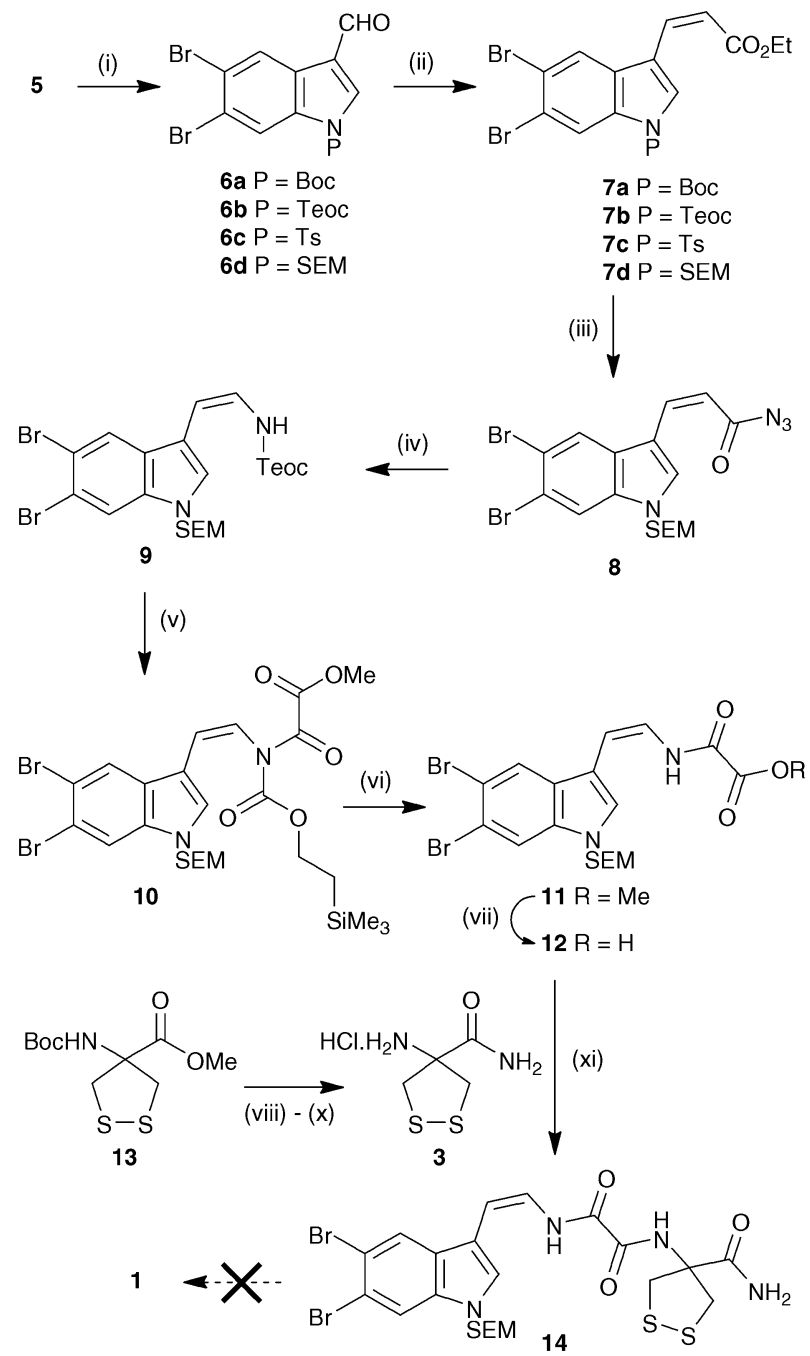

Scheme 2 Synthesis of SEM-protected kottamide E. Reagents and conditions: (i) for 6a: $\mathrm{NaH}$, di-tert-butyl dicarbonate, THF, 95\%; for 6b: NaH, 4-nitrophenyl 2-(trimethylsilyl)ethyl carbonate, THF, 95\%; for $6 \mathrm{c}$ : $\mathrm{NaH}, \mathrm{TsCl}, \mathrm{THF}, 81 \%$; for $6 \mathrm{~d}$ : $\mathrm{NaH}, \mathrm{SEMCl}, \mathrm{THF}, 95 \%$; (ii) $\mathrm{EtO}_{2} \mathrm{CCH}_{2} \mathrm{P}(\mathrm{O})(\mathrm{OPh})_{2}, \mathrm{NaH}, \mathrm{THF},-40{ }^{\circ} \mathrm{C}$. For 7a: $81 \%+$ 13\% (E)-isomer; for $7 \mathrm{~b}: 81 \%+13 \%(E)$-isomer; for 7c: $80 \%$; for $7 \mathrm{~d}: 68 \%+31 \%$ (E)-isomer 15; (iii) aq. $\mathrm{NaOH}, \mathrm{MeOH}, \mathrm{THF}, 65{ }^{\circ} \mathrm{C}$ then $\mathrm{NaH}, \mathrm{DPPA}, \mathrm{THF}, 91 \%$; (iv) $\mathrm{TMSCH}_{2} \mathrm{CH}_{2} \mathrm{OH}$, toluene, reflux, 77\%; (v) NaHMDS, $\mathrm{MeO}_{2} \mathrm{CC}(\mathrm{O}) \mathrm{Cl}, \mathrm{THF}, 0{ }^{\circ} \mathrm{C}$; (vi) TBAF, THF, $0{ }^{\circ} \mathrm{C}, 66 \%$ over 2 steps; (vii) aq. $\mathrm{NaOH}, \mathrm{MeOH}, \mathrm{THF}, 100 \%$; (viii) aq. $\mathrm{NaOH}, \mathrm{THF}, \mathrm{MeOH}, 99 \%$; (ix) $i$-BuOC(O)Cl, $\mathrm{Et}_{3} \mathrm{~N}, \mathrm{THF}, 0{ }^{\circ} \mathrm{C}$ then $\mathrm{NH}_{3}, \mathrm{MeOH}$, $-20{ }^{\circ} \mathrm{C}, 89 \%$; (x) $\mathrm{SOCl}_{2}, \mathrm{MeOH}, 50{ }^{\circ} \mathrm{C}, 100 \%$; (xi) HBTU, DMF, Et ${ }_{3} \mathrm{~N}, 50{ }^{\circ} \mathrm{C}, 66 \%$.

saponification of the ester moiety of $\mathbf{2 0}$ gave carboxylic acid $\mathbf{2 1}$. This was subjected to the previously optimised conditions for amide bond formation with amine 3 . Purification of the reaction mixture required semi-preparative and analytical HPLC to give kottamide $\mathrm{E}$ in modest yield and in approximately $85 \%$ purity, whose spectroscopic data were in agreement with those reported by Appleton and Cobb.,14

In conclusion, the first total synthesis of kottamide $\mathrm{E}$ has been achieved in 8 steps starting from the known dibromoindole $\mathbf{5}$, itself prepared in three steps from commercially available methyl indole-3-carboxylate. The successful approach necessitated a change in protecting group strategy, but still suffered from a modest-yielding final step and recourse to purification by HPLC. This, along with the lack of tolerance towards a wide 
<smiles>O=Cc1cn(S)c2cc(Br)c(Br)cc12</smiles><smiles>C1=C[C@H]2CC[C@H]1C2</smiles>

$6 c$<smiles>CC(C)(C)OC(=O)/C=C\c1cn(S)c2cc(Br)c(Br)cc12</smiles><smiles>CC(C)CC(=O)N/C=C\c1cn(C)c2cc(Br)c(Br)cc12</smiles><smiles>NC(=O)/C=C\c1cn([125I])c2cc(Br)c(Br)cc12</smiles>

(iv)<smiles>COC(=O)C(=O)N/C=C\c1cn(S)c2cc(Br)c(Br)cc12</smiles>
20 (ii)

(ii)

18<smiles>[CH]1C[CH]C1</smiles>

(vi)

Scheme 3 Total synthesis of kottamide E. Reagents and conditions: (i) $t-\mathrm{BuO}_{2-}$ $\mathrm{CCH}_{2} \mathrm{P}(\mathrm{O})(\mathrm{OPh})_{2}, \mathrm{NaH}, \mathrm{THF},-78{ }^{\circ} \mathrm{C}, 78 \%+5 \%(E)$-isomer; (ii) TFA, $\mathrm{CH}_{2} \mathrm{Cl}_{2}$ then $\mathrm{NaH}$, DPPA, THF; (iii) TMSCH $\mathrm{CH}_{2} \mathrm{OH}$, toluene, reflux; (iv) $\mathrm{NaHMDS} \mathrm{MeO}_{2} \mathrm{CC}(\mathrm{O}) \mathrm{Cl}$, THF then TBAF, THF, 32\% over 5 steps; (v) aq. $\mathrm{NaOH}, \mathrm{MeOH}, \mathrm{THF}, 97 \%$; (vi) $3 \cdot \mathrm{HCl}$, HBTU, DMF, Et ${ }_{3} \mathrm{~N}, 38 \%$.

range of SEM deprotection conditions, suggests an inherent sensitivity of the natural product that means the choice of final steps in future syntheses of kottamide E should be of particular concern.

We thank EPSRC for funding. The NMR spectrometers used in this research were obtained through Birmingham Science City: Innovative Uses for Advanced Materials in the Modern World (West Midlands Centre for Advanced Materials Project 2), with support from Advantage West Midlands (AWM) and part funded by the European Regional Development Fund (ERDF).

\section{Notes and references}

‡ In order to gain further insight into the stability issues, the minor (E)-enoate 15 from the Ando-modified Horner-Wadsworth-Emmons

reaction was subjected to the same reaction sequence to give $(E)$-enamide 16 (see ESI $\dagger$ for details). Notably the acylation and Teoc-deprotection steps proceeded smoothly and could be conducted on larger scale than in the $(Z)$-series with no decrease in reaction yield. Presumably this is a reflection of the substantially lower steric crowding around the enamide in the $(E)$-series compared to the $(Z)$-series, where, particularly in the case of 10, a planar, conjugated arrangement is difficult to achieve. Similarly, reaction of $(Z)$-enamide 9 with TBAF was significantly faster than the corresponding $(E)$-isomer $(1$ hour at room temperature $v s$. ca. $50 \%$ consumption after 2 days), indicating orders of magnitude difference in reactivity between the two double bond isomers.

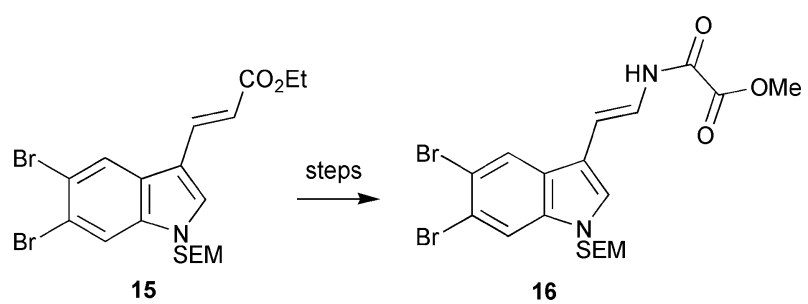

$\S$ The $(E)$-enamide $\mathbf{1 6}$ was also progressed to the same stage but the SEM group again could not be cleanly removed to afford the $(E)$-isomer of kottamide E. See ESI $\dagger$ for details.

1 D. R. Appleton and B. R. Copp, Tetrahedron Lett., 2003, 44, 8963.

2 D. R. Appleton, M. J. Page, G. Lambert, M. V. Berridge and B. R. Copp, J. Org. Chem., 2002, 67, 5402.

3 R. Brettle and A. J. Mosedale, J. Chem. Soc., Perkin Trans. 1, 1988, 2185.

4 K. Kuramochi, H. Watanabe and T. Kitahara, Synlett, 2000, 397.

5 A. B. Smith III and J. Zheng, Synlett, 2001, 1019; A. B. Smith III and J. Zheng, Tetrahedron, 2002, 58, 6455.

6 J. T. Feutrill, M. J. Lilly and M. A. Rizzacasa, Org. Lett., 2002, 4, 525; J. T. Feutrill, M. J. Lilly, J. M. White and M. A. Rizzacasa, Tetrahedron, 2008, 64, 4880.

7 K. Kuramochi, Y. Osada and T. Kitahara, Tetrahedron, 2003, 59, 9447.

8 T. B. Parsons, C. Ghellamallah, L. Male, N. Spencer and R. S. Grainger, Org. Biomol. Chem., 2011, 9, 5021.

9 For a similar approach to 3 see: E. M. Boyd and J. Sperry, Synlett, 2011, 826.

10 For recent syntheses of 5,6-dibromoindole containing natural products, in addition to ref. 8 and 9, see: A. Mollica, A. Stefanucci, F. Feliciani, G. Lucente and F. Pinnen, Tetrahedron Lett., 2011, 52, 2583; J. Sperry, Tetrahedron Lett., 2011, 52, 4042; J. Sperry, Tetrahedron Lett., 2011, 52, 4537.

11 K. Ando, J. Org. Chem., 1997, 62, 1934; K. Ando, J. Org. Chem., 1999, 64, 8406.

12 E. Morera, M. Nalli, F. Pinnen, D. Rossi and G. Lucente, Bioorg. Med. Chem. Lett., 2000, 10, 1585; E. Morera, G. Lucente, G. Ortar, M. Nalli, F. Mazza, E. Gavuzzo and S. Spisani, Bioorg. Med. Chem., 2002, 10, 147.

13 See ESI $\dagger$ for a complete list of conditions with references.

14 We have been unable to identify the impurities present in the aliphatic region of the NMR spectra of synthetic 1 . 